\title{
Influence of Mycorrhiza and Different Yeast Strains on Physical, Chemical and Organoleptic Properties of Graševina (Vitis vnifera L.) Wine
}

\author{
By Valentina Obradovic * \\ Josip Mesic ${ }^{\dagger}$ \\ Brankica Svitlica \\ Maja Ergovic Ravancic ${ }^{\bullet}$
}

\begin{abstract}
The object of the mycorrhizal association between vine and fungus is to increase the absorption of water and/or nutrients from the soil. The aim of this research was to investigate the influence of mycorrhiza to the final product-wine. Besides, for the fermentation process authentic yeasts and four different commercial strains of yeasts were used. Grapes were grown in the wine growing region of Kutjevo, Croatia, in 2013. A typical variety from this region is Graševina. Obtained samples of wines were tested for alcohol, total acids, total polypfenol content (Folin-ciocalteu method), antioxidant activity (ABTS and DPPH method) and color hue. Sensory evaluation was done by professional tasters. Results showed that the usage of the different starter cultures of yeasts had different influences on wine depending on the mycorrhiza. Samples with mycorrhiza had a good extraction of polyphenols with the usage of authentic yeasts, while without micorrhiza starter cultures showed better results, which was evident in the physical and sensory properties as well.
\end{abstract}

Keywords: Graševina, mycorrhiza, polyphenols, yeasts

\section{Introduction}

Graševina is the most widely spread white grape variety in Croatia. The most important synonyms are: Italien Riesling (Romania), Olasz Rizling (Hungary) Laški Rizling (Slovenia, Serbia), Welschriesling (Austria, Germany and Switzerland) (Robinson et al., 2012). It gives fine wines of average and outstanding quality, pleasant varietal aroma and flavor, with a medium content of acid (Mirošević and Turković, 2003). In years in which the grape ripens normally, the wine is a clear greenish-yellow, or yellow with green tinges. It is delicate, moderately to well pronounced, with a complex fruity, floral aroma with a bouquet of almonds (Mirošević et al., 2011).

The study was conducted in the Kutjevo vineyards, which have over the years become synonymous of high quality Graševina wines. The Kutjevo vineyards spread on the southern slopes of Papuk and Krndija at altitudes from

\footnotetext{
${ }^{*}$ Higher Lecturer, Polytechnic of Pozega, Croatia.

${ }^{\dagger}$ Higher Lecturer, Polytechnic of Pozega, Croatia.

* Professor, Polytechnic of Pozega, Croatia.

- Lecturer, Polytechnic of Pozega, Croatia.
} 
200 to 400 meters (Mirošević et al., 2011). The average annual air temperature is around $10.5{ }^{\circ} \mathrm{C}$, and the mean annual temperature is characteristic for a continental climate. The vegetation flow temperature and rainfall allow proper course stages of the annual biological cycle of the vine (Maletić et al., 2008).

Mycorrhiza is a symbiosis of plants and fungi in this case the fungi are at the root of the vine. An important factor influencing mineral uptake is the symbiotic association formed between the root and mycorrhiza fungus (Jackson, 2014). Many researches confirmed the favourable impact of mycorrhiza on vegetative growth of the vine primarily because it enhances nutrients (mostly $\mathrm{P}$ and $\mathrm{N}$ ) uptake and increases tolerance of vine to abiotic stresses (water stress, soil salinity, heavy metals) (Karoglan et al, 2015, Trouvelot et al., 2015). From that point of view $\mathrm{P}$ is particularly interesting because it is very important for plant growth, but it is often poorly available to plants due to its low solubility and mobility (Smith et al., 2011). Previous research (Karoglan et al. 2015) has shown mycorrhiza influence on yield and composition of grapes, but to the best of our knowledge there are no data about the influence on the chemical and sensory quality of wine as a final product.

The principal yeast specie involved in the grape must fermentation, particularly Saccharomyces cerevisiae, comprise a very large number of strains with varied technological properties (Ribereau-Gayon et al., 2007). The yeast strains involved in the winemaking process, influence the fermentation speed, the nature and quantity of the secondary products formed during alcoholic fermentation, and the aromatic characters of the wine (Robinson et. al., 2012).

The aim of this research was to determine the effect of mycorrhiza and different yeast strains to physicochemical parameters and the sensory quality of the Graševina wine from 2013.

\section{Materials and Methods}

\section{Materials}

This research is conducted in the vineyards and the cellar of Polytechnic in Požega. Grapes of the Graševina (Vitis vinifera L.) variety were used for the experiment. The vineyard is situated on southern slopes of Papuk mounteen at an altitude $250 \mathrm{~m}$. It belongs to the Eastern Slavonia region, the Kutjevo sub region.

The mycorrhization of vine is done on June the $7^{\text {th }} 2013$. The application of micorrhizal preparation was done in a way that the Mycoflor solution is injected in the root zone in the depth $30-40 \mathrm{~cm}$.

Grapes were manually harvested on September the $24^{\text {th }}$ of 2013 . The average yield per vine was $1.0-1.5 \mathrm{~kg}$. The amount of grapes used for the research was $50 \mathrm{~kg} / 1$ repetition (25L of must/1 repetition). The sugar level in the grape must from vine without micorrhiza treatment was between 106 and $113{ }^{\circ} \mathrm{Oe}$, and in the must from vine with micorrhiza was between 106 and 116 
${ }^{\circ}$ Oe. The total acidity of the must was $8.5-9.5 \mathrm{~g} / \mathrm{L}$. After the crushing and pressing of the grapes (mechanical press), must is put in tanks for precipitation. After 24 hours, clear must is decanted into fermentation barrels and starter cultures of yeasts were added. Besides commercial starter cultures, fermentation of both musts (with and without micorrhizal treatment) is also done by authentic yeasts.

By the combination of treatments the following samples were obtained:

GRKI-control sample, vine is not treated with micorrhiza and fermentation is done by authentic yeasts.

GRMI-vine is treated with micorrhiza and fermentation is done by authentic yeasts.

GRKII-control sample, vine is not treated with micorrhiza and fermentation is done by starter culture of yeast strain Siha active 7 .

GRMII- vine is treated with micorrhiza and fermentation is done by starter culture of yeast strain Siha active 7.

GRKIII- control sample, vine is not treated with micorrhiza and fermentation is done by starter culture of yeast strain Siha White arome.

GRMIII- vine is treated with micorrhiza and fermentation is done by starter culture of yeast strain Siha White arome.

GRKIV- control sample, vine is not treated with micorrhiza and fermentation is done by starter culture of yeast strain Uvaferm CEG.

GRMIV- vine is treated with micorrhiza and fermentation is done by starter culture of yeast strain Uvaferm CEG.

GREX- control sample, vine is not treated with micorrhiza and fermentation is done by starter culture of yeast strain Anchor Exotics.

\section{Total Polyphenols Determination}

Polyphenols were determined according to the Folin-Ciocalteu method (Sharma et al., 2012, with modifications). An aliquot of wine $(200 \mu \mathrm{L})$ was mixed with $2 \mathrm{~mL}$ of water and of $100 \mu \mathrm{L}$ Folin-Ciocalteu reagent (Kemika, Croatia). The mixture was allowed to equilibrate for 5 minutes, and then 300 $\mu \mathrm{L}$ of sodium carbonate solution $(20 \%)$ was added. After incubation at room temperature in the dark for $30 \mathrm{~min}$, the absorbance of the mixture was read at $725 \mathrm{~nm}$ (Camspec M501, UK). Acidified methanol was used as a blank. The total polyphenols were determined with 3 replications. Gallic acid (Carlo Erba reagents, Italy) was used as a standard (calibration curve $\mathrm{y}=0.1602 \mathrm{x}-0.0008$, $\mathrm{R}^{2}=0.9998$ ), and results were expressed in $\mathrm{mg}$ of gallic acid equivalents per liter.)

\section{Antioxidant Activity Determination (ABTS)}

ABTS.$^{+}$radical was obtained by mixing $7.4 \mathrm{mM}$ ABTS (Fluka, Switzerland) solution and $2.6 \mathrm{mM}$ solution of ammonium persulfate in 1:1 ratio. The solution was left in the dark through the night in order to develop 
stable radical, and then the radical solution was diluted with ethanol in 2:70 ratio to obtain an absorbance of approximately 1.100 ( $\mathrm{A}_{\mathrm{ABTS}}$ ). An aliquot of wine, was mixed with $3.2 \mathrm{~mL}$ of diluted ABTS ${ }^{+}$radical. After incubation at room temperature in the dark for $95 \mathrm{~min}$, the absorbance of the mixture was read at $734 \mathrm{~nm}\left(\mathrm{~A}_{\mathrm{EXTR}}\right)$, and $\Delta \mathrm{A}$ was calculated as $\mathrm{A}_{\mathrm{ABTS}}-\mathrm{A}_{\text {EXTR. Trolox }}$ (Sigma Aldrich, USA) was used as a standard. The decrease in absorbance caused by trolox was done in the same way as for the samples, and standard curve $\Delta \mathrm{A} /$ trolox concentration was created $\left(\mathrm{y}=496.11 \mathrm{x}-18.506, \mathrm{R}^{2}=\right.$ 0.9962 ). Determination of antioxidant activity was done in 3 replications. The results were expressed in $\mu \mathrm{mol}$ of the trolox equivalents per liter.

\section{Antioxidant Activity Determination (DPPH)}

An aliquot of wine $(50 \mu \mathrm{L})$ is mixed with $2 \mathrm{~mL}$ DPPH of radical solution $(0.1 \mathrm{mM}$ in ethanol). The absorbance of the mixture is read at $517 \mathrm{~nm}$ during a period of $30 \mathrm{~min}$, the results were expressed as the mean of 3 replications. Pure ethanol is used as a blank.

$\%$ inhibition $\left.=\left[/ \mathrm{A}_{0}-\mathrm{A}_{\mathrm{t}}\right) / \mathrm{A}_{0}\right] \times 100$

$\mathrm{A}_{0}$ - absorbance of DPPH radical solution.

$\mathrm{A}_{\mathrm{t}}-$ absorbance after 30 minutes.

\section{Colour Hue Determination}

The colour hue was determined by Hanna Instruments HI 83742 instrument according to the instruction manual. The results were expressed as the mean of three repetitions.

\section{Alcohol, Total Acidity, $\mathrm{SO}_{2}$ Determination}

Alcohol strength by volume and total acidity were determined according to the official OIV methods (OIV-MA-AS312-01A, OIV-MA-AS313-01). SO was determined according to the Ripper procedure (Wahl and Converse, 1980).

\section{Sensory Evaluation}

Wines were evaluated according to the 100 points OIV official method (O.I.V., 2001) by the panel of 11 professional tasters. The results were expressed as the mean value.

\section{Data Analysis}

The chemical composition data were analysed by Statistica 12 software, using post hoc $L S D$ at $95 \%$ level. 


\section{Results and Discussion}

Wine phenolics belong to two main groups, non-flavonoid (namely, hydroxybenzoic acid and hydroxycinnamic acid and their derivatives, stilbenes and phenolic alcohols) and flavonoid (namely, anthocyanins, flavan-3-ol monomers and polymers, flavonols and dihydroflavonols) (Castillo-Sanchez et al., 2008). Wine phenolics are considered to scavenge reactive oxygen species, to inhibit oxidation of oil systems, and to inhibit human low-density lipoprotein (LDL) oxidation (Roussis et al., 2008). When using the Folin-Ciocalteu method for polyphenols determination, it is very important to have a low value of free $\mathrm{SO}_{2}$ (as shown in Table 1), because Folin-Ciocalteu reagent reacts not only with polyphenols, but also with other compounds with high antioxidant activity, especially ascorbic acid. Inorganic ions $\mathrm{Fe}^{2+,} \mathrm{Mn}^{2+,} \mathrm{I}-$, and $\mathrm{SO}_{3}{ }^{2-}$ also showed reactivity toward this reagent (Everette et al., 2010).

Table 1. Alcohol, Total Acids and the Amount of $\mathrm{SO}_{2}$ in Samples ${ }^{A, B}$

\begin{tabular}{|c|c|c|c|c|}
\hline Sample & Alcohol (vol\%) & $\begin{array}{c}\text { Total acid } \\
(\mathbf{g} / \mathbf{L})\end{array}$ & $\begin{array}{c}\text { Free SO } \\
(\mathbf{m g} / \mathbf{L})\end{array}$ & $\begin{array}{c}\text { Total } \mathbf{S O}_{2} \\
(\mathbf{m g} / \mathbf{L})\end{array}$ \\
\hline GRKI & $14.30 \pm 0.03^{\mathrm{b}}$ & $7.65 \pm 0.14^{\text {ab }}$ & $3.46 \pm 0.06$ & $60.42 \pm 0.20$ \\
\hline GRKII & $13.03 \pm 0.04^{\mathrm{a}}$ & $7.48 \pm 0.11^{\mathrm{a}}$ & $5.76 \pm 0.08$ & $73.60 \pm 0.23$ \\
\hline GRKIII & $14.60 \pm 0.03^{\mathrm{d}}$ & $7.85 \pm 0.28^{\mathrm{bc}}$ & $4.86 \pm 0.11$ & $65.79 \pm 0.18$ \\
\hline GRKIV & $14.31 \pm 0.01^{\mathrm{b}}$ & $7.40 \pm 0.00^{\mathrm{a}}$ & $5.76 \pm 0.08$ & $70.40 \pm 0.06$ \\
\hline GRMI & $14.32 \pm 0.00^{\mathrm{b}}$ & $7.95 \pm 0.14^{\text {cd }}$ & $3.97 \pm 0.12$ & $51.20 \pm 0.12$ \\
\hline GRMII & $14.50 \pm 0.00^{\mathrm{c}}$ & $8.05 \pm 0.07^{\text {cd }}$ & $4.22 \pm 0.06$ & $45.31 \pm 0.08$ \\
\hline GRMIII & $14.51 \pm 0.01^{\mathrm{c}}$ & $7.93 \pm 0.04^{\mathrm{bc}}$ & $5.50 \pm 0.04$ & $50.43 \pm 0.23$ \\
\hline GRMIV & $14.79 \pm 0.01^{\mathrm{e}}$ & $7.85 \pm 0.07^{\mathrm{bc}}$ & $6.40 \pm 0.11$ & $62.72 \pm 0.28$ \\
\hline GREX & $14.31 \pm 0.01^{\mathrm{b}}$ & $8.00 \pm 0.14^{\text {cd }}$ & $6.66 \pm 0.10$ & $56.96 \pm 0.16$ \\
\hline
\end{tabular}

${ }^{\mathrm{A}}$ Results were expressed as the mean of three repetitions \pm standard deviation.

${ }^{\text {в }}$ Means followed by the same letter in the columns are not statistically different at $5 \%$ probability.

Figure 1. Polyphenols in Samples ${ }^{A, B}$

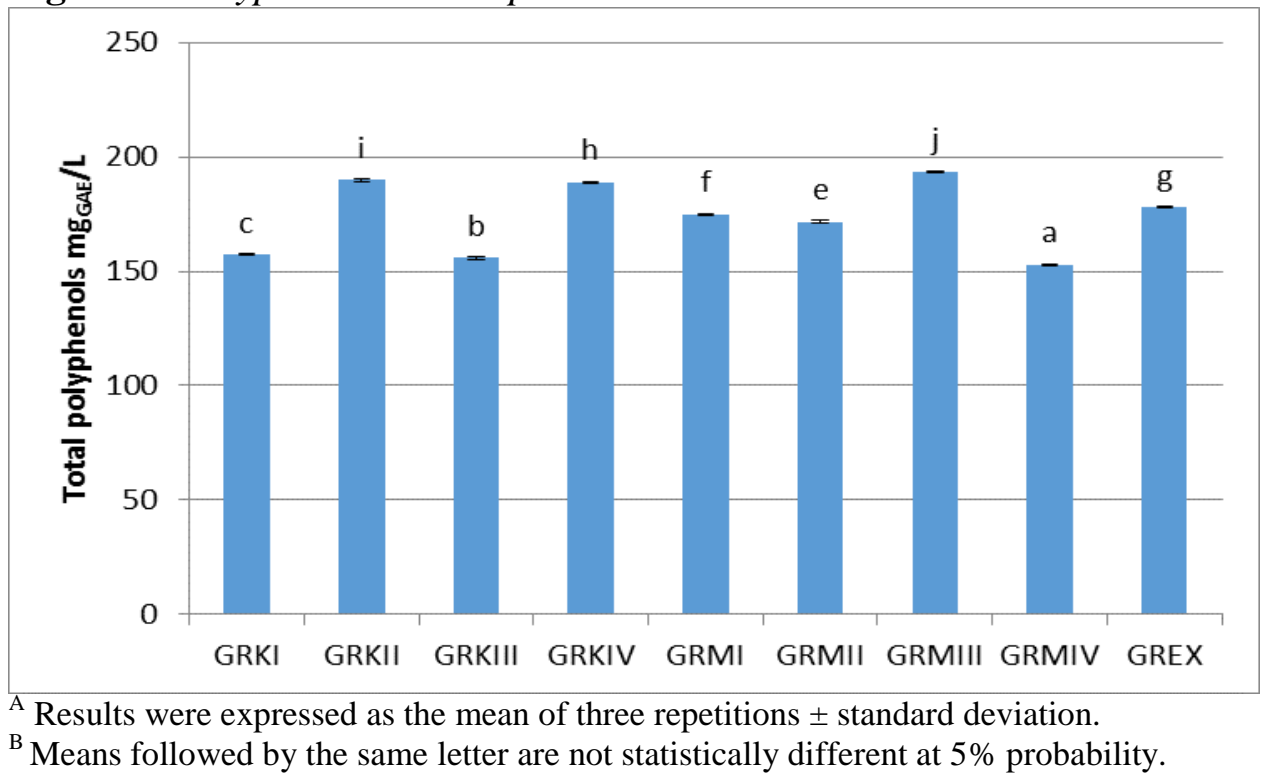


Winemaking techniques and oenological practices strongly affect the phenolic composition of red (Baiano et al., 2009), and white wines (Hernaz et al., 2007; Hernanz et al., 2009) As presented in Figure 1 the amount of total polyphenols in all samples is between $152.67 \mathrm{mg}_{\mathrm{GAE}} / \mathrm{L}$ (GRMIV) and 188.80 $\mathrm{mg}_{\mathrm{GAE}} / \mathrm{L}$ (GRKIV), which is the typical value for the white wines (Roussis et al., 2008; Kallithraka, 2009). It can be seen that the extraction of polyphenols is under the significant influence of the yeast strain used for fermentation. Easy adaptability of yeast strains Siha 7 and Uvaferm CEG resulted in better extraction of the polyphenols to wines, but only in samples without mycorrhiza. On the other hand, in wines with mycorrhiza authentic yeasts also provided relatively similar results compared to Siha 7 yeast strain (174.62 $\mathrm{mg}_{\mathrm{GAE}} / \mathrm{L}$ and $171.50 \mathrm{mg}_{\mathrm{GAE}} / \mathrm{L}$, respectively), but the highest amount of polyphenols was determined in sample GRMIII.

Although polyphenols are the most important and the most popular antioxidants in wines there are also other molecules with antioxidant properties like carotenoids or products of Maillard reactions (Moreno at al., 2007). The correlation of antioxidant activity and polyphenolic content also depends on the method. ABTS and DPPH methods have gained popularity for the study of the antioxidant activity of wines due to their speed and simplicity, and both of them are based on free-radical scavenging activity.

Figure 2. Antioxidant Activity in Samples $(A B T S)^{A, B}$

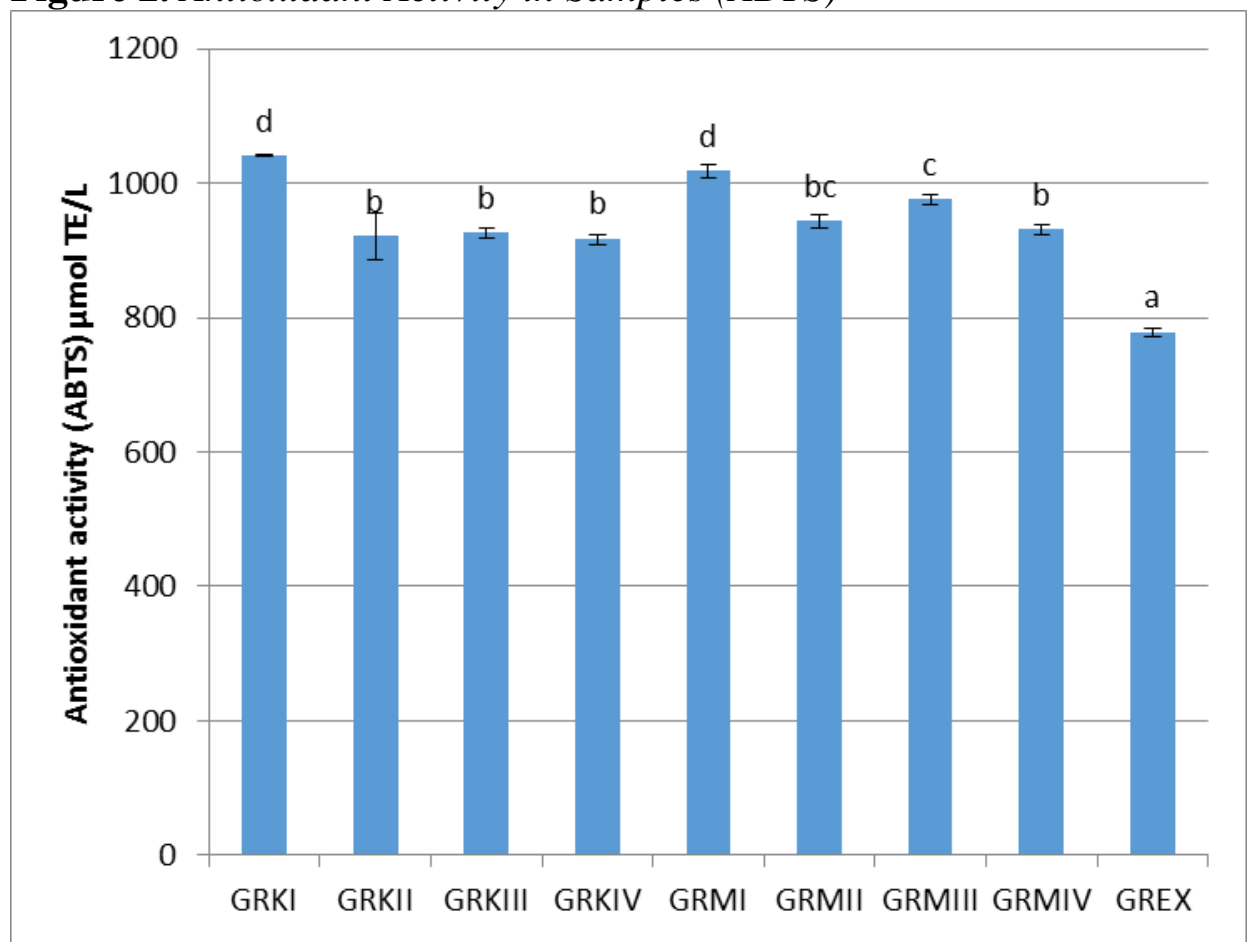

\footnotetext{
${ }^{\text {A }}$ Results were expressed as the mean of three repetitions \pm standard deviation.

${ }^{\mathrm{B}}$ Means followed by the same letter are not statistically different at $5 \%$ probability.
}

Baiano et al. (2009) showed low correlation between the amount of polyphenols in wines and antioxidant activity. They also concluded that 
besides the previously mentioned antioxidants, antioxidant activity depends not only on the phenolic concentration, but also on the specific chemical structure of each phenolic compound. Previous researches showed good a correlation between the total polyphenols content and antioxidant activity in red wines (Büyüktuncel et al., 2014, Piljac-Žegarac et al., 2007), while the correlation in white wines varieties was low (Piljac-Žegarac et al., 2007). As it can be seen (Figures 2 and 3 ) antioxidant activity shows very bad correlation to polyphenol content regardless of the method used for antioxidant activity determination. The highest antioxidant activity (ABTS method) showed wines produced by authentic yeasts, but exotic yeast strains resulted in very low antioxidant activity. The results obtained by the DPPH and ABTS method have a bad linear correlation $\left(\mathrm{R}^{2}=0.256\right)$. When expressed as a percentage of DPPH radical inhibition, samples with mycorrhiza showed higher values of inhibition in period of 30 minutes than samples without micorrhiza.

Figure 3. Inhibition of DPPH Radical after 30 Minutes

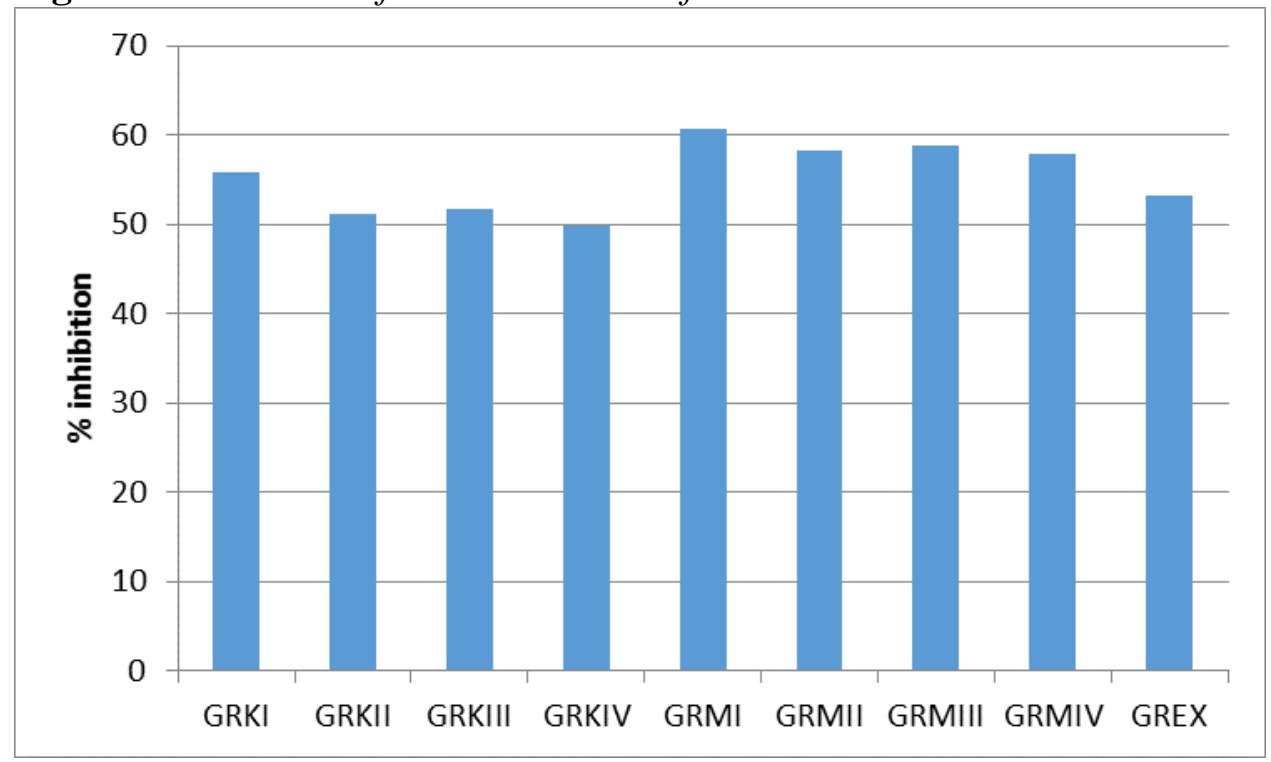

The highest value for the colour hue from the samples without micorrhiza showed sample GRKIV (Figure 4), the same as for the polyphenols. In samples with micorrhiza the highest plyphenolic content and the higest value for colour hue had the sample GRMIII. Although the colour depends on other compounds besides polyphenols (carotenoids, browning reactions products), in this case it can be seen that is directly connected to the level of polyphenols. 
Figure 4. Colour Hue of the Samples ${ }^{A, B}$

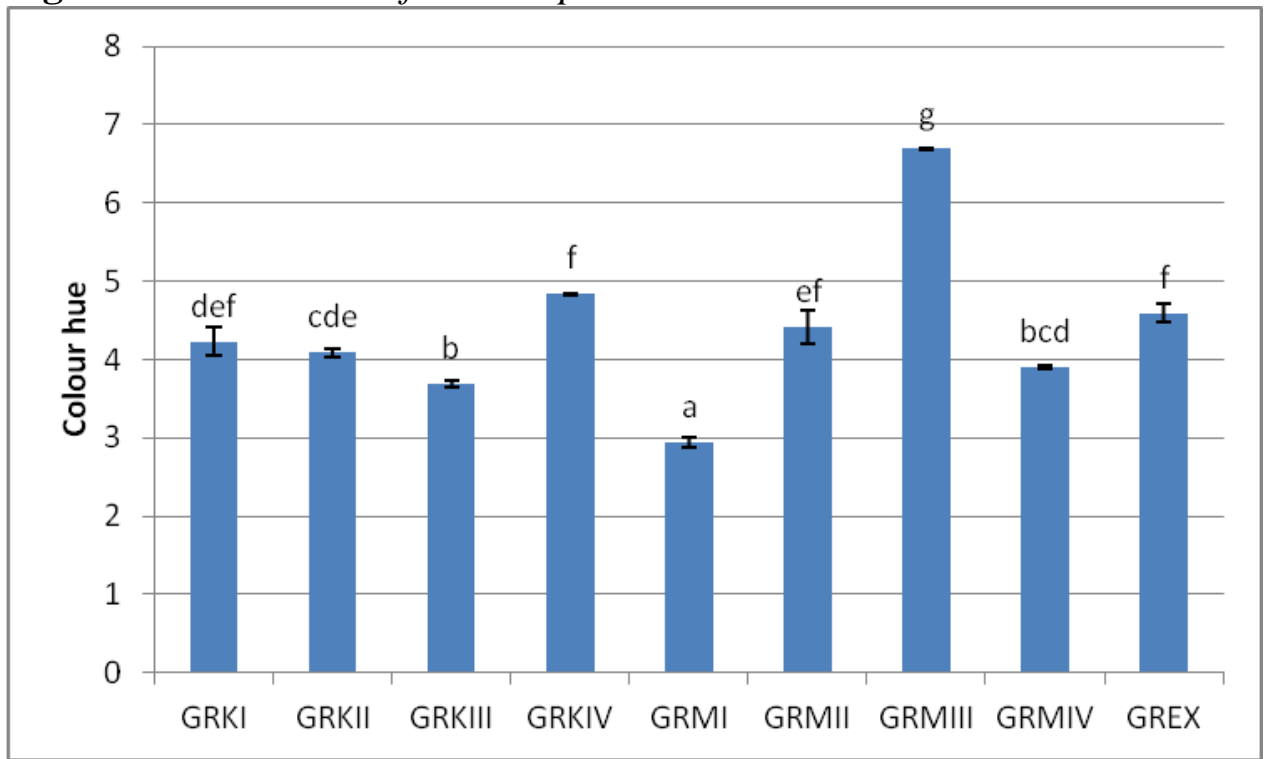

${ }^{\mathrm{A}}$ Results were expressed as the mean of three repetitions \pm standard deviation.

${ }^{\mathrm{B}}$ Means followed by the same letter are not statistically different at $5 \%$ probability.

Table 2 shows the average value of properties: appearance (clarity, color), odor (cleanliness, intensity, quality), flavour (cleanliness, intensity, durability, quality), harmony and overall rate for Graševina wine, harvest 2013.

Table 2. The Appearance (Clarity, Color), Odor (Cleanliness, Intensity, Quality), Flavour (Cleanliness, Intensity, Durability, Quality), Harmony and Overall Rate, Graševina Wine, 2013

\begin{tabular}{|c|c|c|c|c|c|c|c|c|c|}
\hline Graphics & $\begin{array}{c}\text { GR } \\
\text { KI }\end{array}$ & $\begin{array}{c}\text { GR } \\
\text { MI }\end{array}$ & $\begin{array}{c}\text { GR } \\
\text { KII }\end{array}$ & $\begin{array}{c}\text { GR } \\
\text { MII }\end{array}$ & $\begin{array}{c}\text { GR } \\
\text { KIII }\end{array}$ & $\begin{array}{c}\text { GR } \\
\text { MIII }\end{array}$ & $\begin{array}{c}\text { GR } \\
\text { KIV }\end{array}$ & $\begin{array}{c}\text { GR } \\
\text { MIV }\end{array}$ & $\begin{array}{c}\text { GR } \\
\text { EX }\end{array}$ \\
\hline Clarity & 5 & 5 & 5 & 5 & 5 & 5 & 5 & 5 & 5 \\
\hline Colour & 10 & 10 & 10 & 10 & 10 & 10 & 10 & 10 & 10 \\
\hline Appearance & $\mathbf{1 5}$ & $\mathbf{1 5}$ & $\mathbf{1 5}$ & $\mathbf{1 5}$ & $\mathbf{1 5}$ & $\mathbf{1 5}$ & $\mathbf{1 5}$ & $\mathbf{1 5}$ & $\mathbf{1 5}$ \\
\hline Cleanliness & 4.3 & 4.5 & 3.9 & 4.2 & 4.3 & 4.1 & 4 & 4 & 3.9 \\
\hline Intensity & 5.6 & 5.9 & 5.1 & 5.6 & 5.5 & 5.5 & 5.4 & 5.6 & 5.4 \\
\hline Quality & 12.2 & 12.5 & 11.3 & 11.8 & 11.6 & 11.8 & 11.8 & 11.5 & 11.3 \\
\hline Odour & $\mathbf{2 2 . 1}$ & $\mathbf{2 2 . 9}$ & $\mathbf{2 0 . 3}$ & $\mathbf{2 1 . 6}$ & $\mathbf{2 1 . 4}$ & $\mathbf{2 1 . 4}$ & $\mathbf{2 1 . 2}$ & $\mathbf{2 1 . 1}$ & $\mathbf{2 0 . 6}$ \\
\hline Cleanliness & 4.3 & 4.6 & 4.4 & 4.4 & 4.8 & 4.5 & 4.3 & 4.1 & 4.5 \\
\hline Intensity & 6.5 & 6.5 & 5.6 & 6.2 & 6.3 & 6.4 & 6.5 & 6.2 & 6.4 \\
\hline Durability & 6.4 & 6.6 & 5.8 & 5.8 & 6.4 & 6.5 & 6.3 & 6.3 & 6.2 \\
\hline Quality & 16.5 & 16.5 & 16.5 & 16.3 & 16.8 & 17.1 & 16.3 & 14.9 & 16 \\
\hline Flavour & $\mathbf{3 3 . 7}$ & $\mathbf{3 4 . 2}$ & $\mathbf{3 2 . 3}$ & $\mathbf{3 2 . 7}$ & $\mathbf{3 4 . 3}$ & $\mathbf{3 4 . 5}$ & $\mathbf{3 3 . 4}$ & $\mathbf{3 1 . 5}$ & $\mathbf{3 3 . 1}$ \\
\hline Harmony & 9.3 & 9.3 & 9.2 & 9.2 & 9.6 & 9.6 & 9.2 & 9.1 & 9.6 \\
\hline Overall rate & $\mathbf{8 0 . 1}$ & $\mathbf{8 1 . 4}$ & $\mathbf{7 6 . 8}$ & $\mathbf{7 8 . 5}$ & $\mathbf{8 0 . 3}$ & $\mathbf{8 0 . 5}$ & $\mathbf{7 8 . 8}$ & $\mathbf{7 6 . 7}$ & $\mathbf{7 8 . 3}$ \\
\hline & & & & & & & & \\
\hline
\end{tabular}


Considering that wines have not been filtered and there were no colour defects, clarity and colour of all samples were graded with maximum points. Wines fermented with authentic yeasts had better scores for odour (22.1 and 22.9 out of a maximum 30) than the wines fermented with other yeast strains, regardless of micorrhizal treatment. The minimum score for odour is assigned to wine fermented by exotic yeast strains. Out of the maximum 44 points, the highest score for flavour was assigned to the sample GRMIII, followed by GRKIII. As previously mentioned the same sample had the highest amount of polyphenols and the highest colour hue. Usage of yeast strain Siha White arome results with very good chemical characteristics and fruity taste of white wines, which was recognised by panellists and confirmed by chemical analysis. Samples obtained by fermentation with authentic yeasts also had very good scores for flavour. In general, samples with micorrhizal treatment had better scores for flavour than control samples fermented by the same yeast. The overall rate was the highest for wines produced by authentic yeasts, followed by the Siha White arome yeasts. In three of four cases wines with micorrhizal treatment had a higher overall rate.

\section{Conclusions}

Both treatments used in this study, mycorrhizal treatment and usage of different yeast strains had a significant influence on all analysed parameters. Siha White arome yeast strain showed the best results considering polyphenols, colour hue and sensory evaluation. Authentic yeast strain showed very good results in sensory evaluation and antioxidant activity. Polyphenols content and antioxidant activity showed a low correlation regardless the method used for antioxidant activity determination. Wines obtained from grapes with micorrhizal treatment compared to the control wines showed better results for all tested parameters. Additional researches are needed in the field of mineral content in wines as well as the repetition of research in the following year.

\section{References}

Baiano, A., Terracone, C., Gambacorta, G., La Notte, E. 2009. Phenolic content and Antioxidant Activity pf Primitivo wine: Comparison among Winwmaking Technologies. Journal of food science 74(3), 258-267.

Büyüktuncel, E., Porgah, E., Colak, C. 2014. Comparison of total phenolic content and antioxidant activity in local red wines determined by spectrophotometric methods. Food and Nutrition Sciences 5, 1660-1667.

Castillo-Sanchez, J. X., Garcia-Falcon, M. S., Garrido, J., Martinez-Carballo, E., Martins-Dias, L. R., Mejuto, X. C. 2008. Phenolic compounds and colour stability of Vinhao wines: Influence of wine-making protocol and fining agents. Food Chemistry 106, 18-26.

Everette, J. D., Bryant, Q. M., Green, A. M., Abbey, Y. A., Wangila, G. W., Walker, R. B. 2010. Through study of reactivity of various compound classes toward the 
Folin-Ciocalteu Reagent. Journal of Agricultural and Food Chemistry 58, 81398144.

Hernanz, D., Recamales, A. F., Gonzalez-Miret, M. L., Gomez-Miguez, M. J., Vicario, I. M., Heredia, F. J. 2007. Phenolic composition of white wines with a prefermentative maceration at experimental and industrial scale. Journal of Food Engineering 80, 327-335.

Hernanz, D., Gallo, V., Recamales, A. F., Melendez-Martinez, A. J., Gonzalez-Miret, M. L., Heredia, F. J. 2009. Effect of storage on the phenolic content, volatile composition and colour of white wines from varieties Zalema and Colombard. Food Chemistry 113, 530-537.

Jackson, R. S. 2014. Wine science principles and applications, fourth edition Academic press, San Diego, USA.

Kallithraka, S., Aliaj, L., Makris, D. P., Kefalas, P. 2009. Anthocyanin profiles of major red grape (Vitis vinifera L.) varieties cultivated in Greece and their relationship with in vitro antioxidant characteristics. International Journal of Food Science \& Technology 44(12), 2385-2393.

Karoglan, M., Osrečak, M., Andabaka, Ž., Stupić, D., Kozina, B., Krištof, E., Pavlešić, T. 2015. Influence of mycorrhiza on yield and mechanical composition of grapes cv. Traminer (Vitis vinifera L.). Proceedings $50^{\text {th }}$ Croatian and $10^{\text {th }}$ International Symposium on Agriculture, Milan Pospišil (Eds.), University of Zagreb, Croatia.

Maletić, E., Karoglan Kontić, J., Pejić, E. 2008. Vinova loza ampelografija, ekologija, oplemenjivanje [Vine ampelography, ecology, breeding], Školska knjiga, Zagreb, Croatia.

Mirošević, N., Turković, Z. 2003. Ampelografski atlas [Ampelographic atlas], Golden marketing, Tehnička knjiga, Zagreb, Croatia

Mirošević, N., Vranić, I., Soldo Čamak, V., Božičević, T., Jelaska, V., Maletić, E., Premužić, D., Ivanković, Z., Brkan, B., Ričković, M., Bolić, J. 2011. Kutjevačka Graševina nadarbina Zlatne doline (Vallis aurea) [Kutjevo Graševina the gift of Golden valley (Vallis aurea)], Golden marketing - Tehnička knjiga, Zagreb, Croatia.

Moreno, J., Peinado, J., Peinado, R. A. 2007. Antioxidant activity of musts from Pedro Ximenes grapes subjected to off-vine drying process. Food Chemistry 104, 224 228.

O.I.V. International code of Oenological Practices 2001., Paris.

Piljac-Žegarac, J., Martinez, S., Valek, L., Stipčević, T., Kovačević-Ganić, K. 2007. Correlation between the phenolic content and DPPH radical scavenging activity of selected Croatian wines. Acta Alimentaria 36(2), 185-193.

Ribereau - Gayon, P., Dubourdieu, D., Doneche, B., Lonvaud, A. 2007. Handbook of enology Volume 1 The mikrobiology of Wine and Vinification, second edition, John Wiley and sons, LTD, England.

Robinson, J., Harding, J., Vouillamoz, J. 2012. Wine Grapes a complete guide to 1368 vine varieties, including their origin and flavours. Penguin Books Ltd, London WC2R ORL, England.

Roussis, I. G., Lambropoulos, I., Tzimas, P., Gkoulioti, A., Marinos, V., Tsoupeis, D., Boutaris, I. 2008. Antioxidant activities of some Greek wines and wine phenolic extracts. Journal of Food Composition and Analysis 21, 614-621.

Sharma, P., Gujral, H. S., Singh, B. 2012. Antioxidant activity of barley as affected by extrusion cooking, Food Chemistry 131, 1406-1413.

Smith, S. E., Jakobsen, I., Gronlund, M., Smith, F. A. 2011. Roles of arbuscular mycorrhizas in plant phosphorus nutrition: interactions between pathways of 
phosphorus uptake in arbuscular mycorrhizal roots have important implications for understanding and manipulating plant phosphorus acquisition. Plant Physiology 156, 1050-1057.

Trouvelot, S., Bonneau, L., Redecker, D., van Tuinen, D., Adrian, M., Wipf, D. 2015. Arbuscular mycorrhiza symbiosis in viticulture: a review. Agronomy for sustainable development 35(4), 1449-1467.

Wahl, J. M., Converse, J. E. 1980. Ripper procedure for determing sulphur dioxide in wine: collaborative study. Journal-Association of Official Analytical Chemists 63(2), 194-199. 
